\title{
DYNAMICS OF CERTIFIED ENVIRONMENTAL MANAGEMENT SYSTEMS: ISO 14001 AND EMAS IN ROMANIA
}

\author{
Patricia Rațiu ${ }^{1}$ \\ Maria Mortan ${ }^{2}$
}

\begin{abstract}
Confronted with more complex and numerous environmental issues many companies realized that environmental initiatives can be more effectively managed through an EMS which provide a systematic and coherent approach of their activities.

In the present paper we describe the two most recognized and widely applied systems for environmental management - EMAS (Eco-Management and Audit Scheme) and ISO 14001 certifications. Once viewed as an external cost, environmental responsibility is fast becoming a competitive advantage for companies and for the whole economy of a country. Our paper adds new perspective to the literature framework, by showing that even if the differences between ISO 14001 and EMAS still exist they are not competitors, moreover ISO 14001 requirements are integrated into EMAS scheme, become compatible to each other.

To achieve the objective of this paper we make an analysis regarding the number of Romanian organizations that have a certified environmental management system, in compliance with the two main international references. The results show that in our countries the number of organizations with an EMS certified by ISO 14001 is much higher than the number of organizations registered under EMAS. This represents an opportunity, given that once with the adoption of EMAS II, ISO 14001 is a step stone towards EMAS certification and companies can integrate both standards in their management system, achieving more benefits on the European markets. Another opportunity to increase the number of EMAS registration are economic and financial incentives offered to small and medium sized companies.
\end{abstract}

Keywords: environmental management system, EMAS III, performance improvement, ISO 14001

Jel Codes: $Q 53, Q 56, M 14$

\section{Introduction}

In recent decades, the expansion of economic activity has been accompanied by growing global environmental concerns, such as climate change, energy security and increasing scarcity of resources. Making consumption and production more sustainable means responding to basic needs and improving quality of life while trying to use natural resources in a more responsible way. Moreover, improved efficiency in some regions has been offset by increases in consumption and growth in others. Under the pressures such as growing number of environmental concerns, legislative measures, demands of consumers for environmentally friendly products and services, public pressure, it is becoming more and more important for organizations to demonstrate sustainability of their investment strategies and operations. In response, many companies have

\footnotetext{
${ }^{1}$ Babeş -Bolyai University, Cluj-Napoca, Romania, e-mail: patricia.ratiu@econ.ubbcluj.ro

${ }^{2}$ Babeş- Bolyai University, Cluj-Napoca, Romania, e-mail: maria.mortan@econ.ubbcluj.ro
} 
shown more interest in sustainable production and have adopted systematic methods to integrate in their business both economic activities and environmental issues.

In practice, one tool which companies have generally accepted to extend environmental responsibilities throughout their value chains and to facilitate implementation of environmental policy is an environmental management system (EMS). The adoption of environmental management systems as frameworks for integrating corporate environmental protection policies, programs, and practices is growing among both domestic and multinational companies around the world. (Morrow, Rondinelli, 2002). Into his book, Edwards (2004) considers that there are four reasons why every organization should take environmental factors into account in its management processes: ethical, economic, legal and commercial - more and more large organizations are aware of their environmental responsibilities and they expect their suppliers and subcontractors to do the same. Recently, environmental management has become a key priority for many companies that become aware that cannot survive without consideration the impact of their activities on environment.

In this context, based on a review of relevant literature we highlight that implementing and certifying an EMS not only cover the preservation of the environment but are also linked to business performance and brings a lot of benefits, contributing to the development of companies in a sustainable manner. In order to contribute to the current debate on this topic the paper aims to compare the characteristics of the main international references not with the purpose to highlight the differences between them, on contrary to show that the two standards can be compatible. By analyzing the number of Romanian organizations that have a certified environmental management system, in compliance with EMAS and ISO 14001 another objective of this study is to identify some solutions for increasing the number of EMAS registration that brings more benefits for companies, considering that Romania has to align with the sustainable vision of the European Union.

Finally, the last section provides the main conclusions emerging from our work, as well as limitations and needs for further research.

\section{Methodology}

In order to achieve the objectives of the paper we start with a review of the literature focusing on studies, researches, reports and publications of the European Commission, Member States that help us to achieve an integrated picture of the topic discussed. Also a synthesis review was deemed appropriate because it integrates isolated information into a more comprehensive and internally consistent whole.

The methodology during this study consisted of analyzing the dynamics of certified EMS according to ISO 14001 standard and EMAS scheme, using statistical data. Because we have found differences between data from different sources first challenge was to identify official sources regarding the number of ISO 14001 and EMAS certificates. We investigated the database of European Commission (Eurostat) in order to collect information regarding the number of EMAS sites and organizations. The collection of data on ISO 14001 certified EMS was carried out by checking the official sites of International Standardization Organization and DG ENV (DirectorateGeneral for Environment). Currently, in Romania is in effect the version SR EN ISO 14001: 2005 "Environmental Management Systems. General guidelines on principles, systems and support techniques".

To identify information about those companies that have EMAS registration in Romania (the year of certification, the field of activity and others) we used National Register EMAS from National Agency for Environmental Protection. The competent body responsible for registration of EMAS organization from Romania is Ministry of Environment and Forests - a central public authority, through the department Integrated Control of Pollution and Impact Assessment. Since 2011, EMAS III regulation is translated (transposed) into national legislation. 


\section{Environmental management systems- an overview of literature}

Organizations with a proactive approach to environmental challenges look for ways to continually improve their environmental performance and to integrate their environmental management practices into more comprehensive systems. An environmental management system (EMS) is a worldwide tool potentially applicable by any kind of organization in order to identify environmental aspects, to control the level of environmental performance and reach a continuous improvement of it. The growth of EMS as a process for integrating corporate environmental policies and programs has been quite rapidly over the past decade.

In practice the most environmental management systems are designed and certified according to the main reference standards: the international standard ISO 14001 and European regulation Eco-Management and Audit Scheme (EMAS). A lot of studies show that multinational and domestic corporations around the world are adopting environmental management systems (EMS) and certifying them by these international standards (Biondi et al, 2000; Morrow and Rondinelli, 2002; Matuszak - Flejszman, 2009; Comoglio and Botta, 2012; Boiral and Henri, 2012; Testa et al, 2014).

Indeed third-party certification provides credibility to an organization's EMS. Moreover this is important on a global scale because environmental regulations and management practices differ widely. Also contract partners may associate the quality of your products and services with a verifiable environmental performance. Some authors (Comoglio and Botta, 2012) indicate that EMS implementation increases the number of companies committed (mean increase: $108.7 \%$ ), as well as the number of environmental aspects involved and determines higher investments towards environmental improvement. Data resulted from the same study, show that EMS determined positive effects in the environmental performances, although with highly heterogeneous values, varying from $+16.9 \%$ (use of resources) to $+42.7 \%$ (releases to water).

EMAS was adopted in 1993 as a step towards the Community's goal of sustainable development. Coming into force in April 1995, this voluntary scheme was initially open for participation, only by European organizations and sites operating in industrial sector. In 2001, the legislation was revised with the adoption of EMAS II that includes an extension of the scope of EMAS to all types of organizations in the public and private sector that seek to improve their environmental performance. With the introduction of EMAS III that came into effect on January 2010 the scheme allows Member States to enable EMAS registration for organizations from outside the EU (EMAS Global). (http://ec.europa.eu/environment/emas). The revision aims to increase participation in the scheme, establishing the scheme as a benchmark for environmental management systems and allowing organizations to upgrade their management systems to EMAS.

Developed under the auspices of the International Organisation for Standardisation (ISO) in 1996, ISO 14001 is the most well known and widely implemented standard for the design of an environmental management system (Matuszak -Flejszman, 2009; Nishitani, 2010; Boiral and Henri, 2012; Searcy et al, 2012). This standard is part of the ISO 14000 "family" that addresses various aspects of environmental management. According to Morrow and Rondinelli, (2002:61) ISO 14001 is a set of guidelines by which a facility - a single plant or a whole organization - can establish or strengthen its environmental policy, identify environmental aspects of its operations, define environmental objectives and targets, implement a program to attain environmental performance goals, monitor and measure effectiveness, correct deficiencies and problems, and review its management systems to promote continuous improvement.

Very often organizations, when taking decisions to implement an environmental management system speculate about when and what benefits they can achieve. It stems from the fact that implementing and maintaining an EMS is an expensive process, involves resources such as time, money, humans and therefore the managers want to know if it brings positive effects especially on long term. Such costs become more apparent when a company wants a certification for their EMS. So why do a company need an environmental management system? Maybe a 
successful EMS could bring more benefits than the costs. Indeed much of the research emphasizes that the costs are outweighed by benefits (Rondinelli and Vastag, 2000).

Implementation of environmental management system in one company is more than a matter of image, it has multiple benefits both internal - directly influencing the activity of the company, and external - influencing its surrounding environment:

$>$ achieving continuous improvements in environmental performance,

$>$ managing environmental costs and liabilities,

$>$ improved employee and managerial awareness,

$>$ establishment of new energy efficiency and waste reduction targets,

$>$ identification of pollution prevention opportunities,

$>$ reduction of trade barriers and increase market share,

$>$ compliance with legal requirements,

$>$ better relationships with stakeholders,

$>$ creating competitive advantage.

The following paragraphs provide an overview of the main empirical evidence on the effects and benefits of implementing an environmental management system according to ISO 14001 and EMAS for a better environmental performance among companies.

By observing the influence of ISO 14001 on the environmental performance of companies belonging to the Italian automotive sector and certified for at least three years, Comoglio and Botta (2012), found that an EMS determines positive effects on environmental performance, especially in terms of air emissions, waste management and the use of resources. Also a survey on 121 US firms belonging to several manufacturing sectors, revealed positive quantitative effects on ISO 14001 and the amounts of solid waste generated. (Franchetti, 2011)

In their study Rondinelli and Vastag (2000) found that three years after ISO 14001 certification, managers identified four sets of positive impacts- improvements in employee awareness (through training programs), operational efficiency, managerial awareness, and operational effectiveness. The most significant impact of the ISO 14001 process was in improving the environmental awareness among managers and employees, and in clarifying everyone's responsibility for environmental improvements. We consider that educative component is very important for a better functioning of an EMS and therefore employees' participations to environmental training programs increased their awareness of the environmental aspects of their jobs and of their responsibilities for reducing negative impacts.

Studies that have found a positive relationship between foreign customers and ISO 14001 adoption include Nishitani (2010) and Daddi et al (2013). Here, the basic argument is that ISO 14001 is essential for continued access to foreign markets or, more precisely, many multinational enterprises require ISO 14001 in the global supply chain. For example small companies are quite often suppliers of large enterprises; in case they do not have an environmental management system it is hard for them to compete on the market and retain their position as suppliers of large multinational organizations.

Moreover, holding an ISO 14001 certificate diminishes the risk linked to buying products and services of a given company and increase consumer confidence. As a result, buyers are often willing to pay more for the goods of this supplier than they would pay for goods of a supplier who does not hold the certificate. Despite the fact that the quality of the product or service is still the main criterion in supplier selection, holding an ISO 14001 certificate can create a substantial competitive advantage (Matuszak-Flejszman, 2009).

The demands of the commercial partnerships in the European Union recommend the introduction of an environmental management system under the EMAS registration within the companies of the member states. Also in many countries the national legislation stimulates the choice of this system. The studies show that organizations with EMAS record superior results for eco-management in comparison with other systems and can benefit from a preferential treatment in 
the selection procedures for contracts, loans granting, closing insurance contracts, accessing European funds. (Gara and Muhlberger, 2006)

Another relevant contribution was provided by Rennings et al. (2003). Through a survey of 1277 EMAS-registered German facilities and 12 in-depth case studies, the authors found that environmental managers consider the implementation of EMAS to be a substantial contribution to the introduction of environmental innovations, especially organizational ones.

In addition the research performed by Morrow and Rondinelli (2002), who studied the relationship between EMAS and performance improvement of five German domestic energy and gas companies reported improvements in regulatory compliance and legal certainty, better organization and documentation of their environmental management activities, improvements in employee awareness. Cost savings were not really achieved by German energy and gas firms to implement and certify their environmental management systems. For three of the five companies, ex post analyses showed that cost savings were insignificant.

The study by Daddi et al. (2011) analyzed the trends in environmental performance of a sample of 64 Italian companies of six different industrial sectors which have achieved EMAS registration for at least three years. In particular, the authors analyzed the influence of the EMAS registration on the improvement or worsening of environmental performance, and therefore the ability of this tool to move forward continuous improvement, which is a fundamental principle of the systems of certifications of environmental management. The data obtained indicate that EMAS positively influences performance on some environmental aspects like water consumption, waste and emissions into the atmosphere while the influence on energy consumptions is not clearly confirmed.

The success of both standards relies on their highly flexible requirements which allow any organization to set up an EMS according to its internal characteristics and to identify the most effective solutions to improve their performance.

\section{EMAS and ISO 14001 - compatible or still competitive?}

The differences between ISO 14001 and EMAS have been the subject of considerable debate in both the practitioner and academic literature (Biondi et al, 2000, Morrow and Rondinelli, 2002, Freimann and Walther, 2002; Testa et al, 2014). At the beginning the two standards are seen as competitors, since they pursued the same aim - providing good environmental management, but with some differences. Indeed, while ISO 14001 focuses on improving the management system, EMAS organizations engage to the continuous improvement of their environmental performance beyond legal requirements. (Report EMAS, 2011). This includes stricter requirements on the measurement and evaluation of environmental performance against objectives and targets, as well as regular internal and third-party audits that determine whether the planned improvements of environmental activities have been achieved.

Regarding ISO 14001 certification, the most often heard criticism refers to the fact that it does not measure the actual environmental performance of a plant or company (Brouwer and van Koppen, 2008). Although there is a guideline (ISO 14031) for environmental performance evaluation, it has no requirement to assess whether the organization's environmental performance achieves continuous improvement. The ISO 14001 standard simply assumes that if environmental management system will be implemented effectively, it lead to continuous environmental performance improvement. It is not surprising that the ISO 14001 standard attracted more participants, even though it came into force a year later than EMAS. Some authors bring into attention that organizations that choose EMAS registration have better environmental performance than those choose ISO 14001 certification (Clausen, 2002). Other authors have noted that, although ISO 14001 does not ensure legal compliance or performance improvement, it does serve as an image-building effort for organizations that are already complying with regulations. (Rondinelli and Vastag, 2000). 
In this section we propose to bring into attention the fact that with the amendment of EMAS (EMAS II and EMAS III) the differences between the two references were significantly reduced and the rivalry was defused. The revision process of the EMAS scheme revealed a continuous effort by the European Commission to align the two standards (mainly in terms of requirements) and to highlight that even if some differences still remain the two standards do not exclude each other and their benefits start to become common.

In 2001, the European Commission officially integrated ISO 14001 requirements related to the implementation of an EMS in the EMAS scheme by including the entire text of the IS0 14001 standard as an annex of the revised version of EMAS Regulation (EMAS II). These changes have given rise to some questions:

$>$ The adoption of ISO 14001 requirements into EMAS scheme will allow organizations to progress from ISO 14001 to EMAS certification? European Commission has recognized that ISO 14001 can provide a stepping stone for EMAS registration. A successful certification of ISO 14001 means that the most important steps towards EMAS certification have been taken, but additional issues will be addressed. (http://ec.europa.eu/environment/emas).

$>$ Does EMAS participation lead to an ISO 14001-certificate? Yes, EMAS registration attests that organizations has an environmental management system and complies with the requirements of ISO 14001.

$>$ Do EMAS participants need to pay the double costs of both the EMAS and ISO 14001 audits? Taking into account that EMAS includes all the requirements of ISO 14001, both systems can be validated and certified by one environmental verifier at the same time. Thus, only limited additional costs, if any, are incurred in doing both. (Report, EMAS, 2011).

A second important alignment was to extend the scope of EMAS to all types of organizations from all economic sectors, according to the approach followed by ISO 14001. In addition, EMAS II was strengthened by adopting an attractive EMAS logo that can be used as a marketing or sales tool to promote the organization's excellent environmental performance. (http://ec.europa.eu/environment/emas).

Finally, the latest revision of the EMAS Regulation (EMAS III - is in force since January 2010) aligned the two systems through the extension of the EMAS regulation to non-EU countries. (http://ec.europa.eu/environment/emas). Until then one of the reasons why most companies chose ISO 14001 was its international standard status. This explains why ISO 14001 is the only EMS standard adopted in countries such as the United States and Japan and it is adopted significantly more often than the EMAS scheme in multinational companies (Testa et al, 2014). In this way was improved the applicability and credibility of the scheme and strengthen its visibility and outreach. Now both standards are world-wide recognized and apply to all types of organizations. Despite these efforts to make the two standards more compatible, some differences remain. First, the nature of the two schemes is different. EMAS is issued by a public body while the ISO 14001 standard is a private norm. The differences between the two schemes were also revealed by Neugebauer (2012) that found different external pressures affecting the adoption of the two standards: the choice to adopt ISO 14001 is mainly induced by external stakeholders while the implementation of EMAS is mainly influenced by internal motivations.

Even it is completely compatible with ISO 14001, EMAS sets more stringent requirements for performance improvement, employee involvement, compliance with legal requirements and external communication with stakeholders (figure 1). 


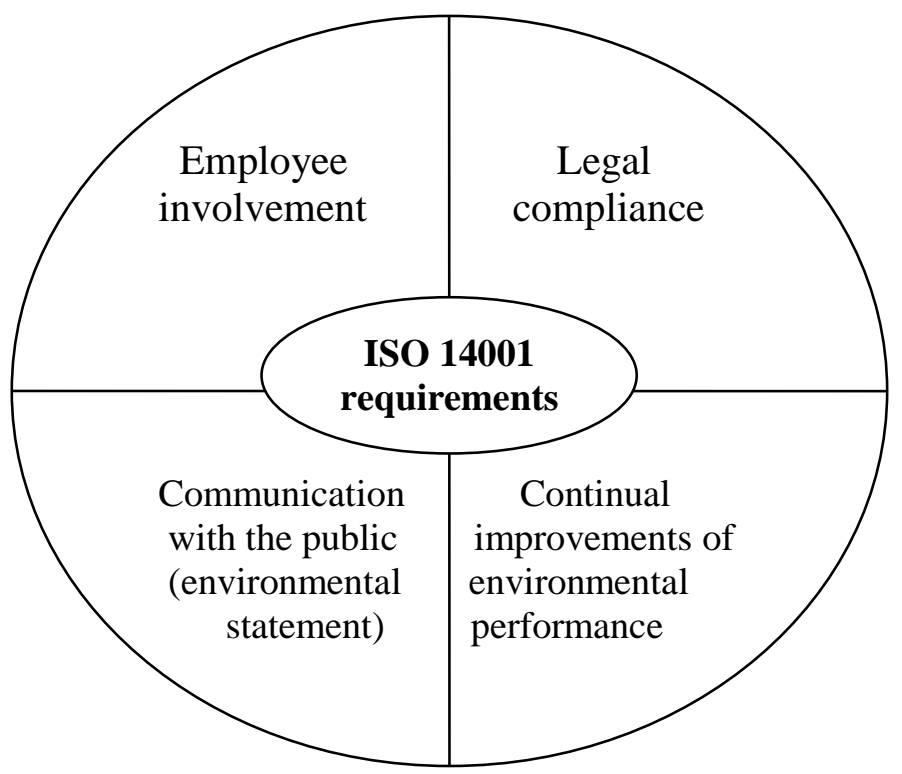

Figure no. 1 - Additional requirements for EMAS registration

Source: Creating added value with EMAS, Report EMAS, 2011

EMAS is the most credible and robust environmental management system on the market, adding several elements on top of the requirements of the international standard for environmental management systems ISO14001:2004.

An organization that has accepted voluntary to participate into EMAS scheme must commit itself to the continuous improvement of its environmental performance. This is recorded and presented in the environmental statement which includes standardized and tangible performance indicators - with regard to the significant environmental aspects such as energy efficiency, material efficiency, waste, water, emissions and biodiversity. (Report EMAS, 2011). These indicators allow not only for comparison within the company, but also for benchmarking within the sector. Improvements and trends can be meaningfully compared over a number of time periods, even if external circumstances change.

Then an EMAS registered organization has to involve employee in the process of continual improvement (through active participation and information). We consider that providing information to employees and actively involving them in the environmental management system is a driving force for innovation and increases their identification with the enterprise and job satisfaction.

Third, the EMAS Regulation sets more stringent requirements on external communication than does ISO 14001. Organizations have to demonstrate an open dialogue with interested parties, including customers, local authorities, suppliers and other stakeholders. Dialogue with the public is an indispensable part of the environmental management system under EMAS (Report EMAS, 2011). One aspect of this public interaction is the environmental statement, a written document which includes key performance indicators of significant environmental aspects, environmental objectives, facts and figures and other relevant information related to organization's environmental impacts and performance. The data reported in the environmental statement has to be validated by an accredited environmental verifier during the certification audit. For this reason, EMAS is considered a better tool to communicate the environmental commitments of companies to external stakeholders. In our opinion by publishing an externally validated environment statement, the transparency of the organizations in preventing and controlling environmental issues is achieved. At the same time, the growth of the prestige and credibility of the companies will lead to better economic performances. For ISO 14001 reports or external communication is not required and only the environmental policy must be made available to the public. 
Not least in order to obtain EMAS organizations must demonstrate full compliance with environmental legislation and how they comply with legal requirements and permits.

Covering the requirements of ISO 14001, while setting additional issues and being worldwide recognized EMAS become the most credible and comprehensive environmental management system for the improvement of environmental performance.

\section{Results and discussion on the dynamics of ISO 14001 and EMAS certifications. The case of Romania}

Taking into account that EMAS and ISO 14001 are the two most recognized and widely applied certification systems for environmental management we want to find to what extant organizations are increasingly engaging to manage environmental issues in a systematic, integrated and sustainable manner. The indicators used are: the number of organizations certified according to the international standard for EMS, ISO 14001 and the total number of organizations and sites registered by EMAS regulation. In order to analysis the evolution of certified EMS according to ISO 14001 standard and EMAS schemes we used two different sources. Firstly, we investigated the database of European Commission (Eurostat) in order to collect information regarding the number of EMAS sites and organizations. The collection of data on ISO 14001 certified EMS was carried out by checking the official sites of International Standardization Organization and DG ENV (Directorate-General for Environment).

The publication of the ISO 14001 standard for environmental managements systems (EMS) in 1996 and then revised in 2004 has proved to be very successful worldwide. According to the recently released "ISO Survey 2012", up to the end of December 2012, a number of 285.844 ISO 14001 certificates had been issued across 167 countries, which represents an increase of 9\% (+ 23.918), compared to previous year. The top three countries for the total number of certificates issued were China (91.950), Japan (27.774) and Italy (19.705), while the top three for growth in the number of certificates in 2012 were China, Spain and Italy. (ISO Survey, 2012).

We notice that China overtook Japan as the nation, both in term of the highest number of overall certifications and annual growth. Much of this has been driven by the export market. A key driving force in the Far East is the fear that environmental management standards may become a barrier to trade, especially in the lucrative European market. Another factor is that the electronics industry has proved particularly keen on ISO 14001. The industry is also encouraging certification along its supply chain and many European companies were certified as a result of decisions by their Asian parent companies. (ENDS, 2013:9).

It is important to mentioned that the same study (ISO Survey, 2012) ranks Romania on the 7th place in the world, regarding ISO 14001 certificates in 2012 (8.633), overtaking countries such as France, Germany and United States. The success of EMAS has kept ISO 14001 certification low in countries such as Germany, where in 2012 the number of organizations with EMAS registration was 1.212 (E.C, Eurostat databases, 2013), being the second country from European Union after Spain and being called "EMAS Land".

Thus our country reached to own a share of $7,61 \%$ of ISO certificates across Europe. Also Romania was ranked 4, regarding annual growth, recording an increase of 1.239 ISO 14001 certificates compared to 2011 (figure 2). Being one of the top ten countries globally is excellent news for Romania - as companies are using ISO 14001 to maintain competitive advantage, cutting costs, enhancing their reputation and winning new business. A trigger for the increased number of ISO 14001 adoptions in Romania may be the pressures of stakeholders, especially on the demand side, as they influence firm profits. Firms therefore attempt to satisfy their stakeholders with ISO 14001 adoption, as this indicates their commitment to environmental management. Indeed, many previous studies that have analyzed the determinants of ISO 14001 adoption have found that environmental preferences and pressures of stakeholders influence the firm's decision (Nishitani, 2010). 


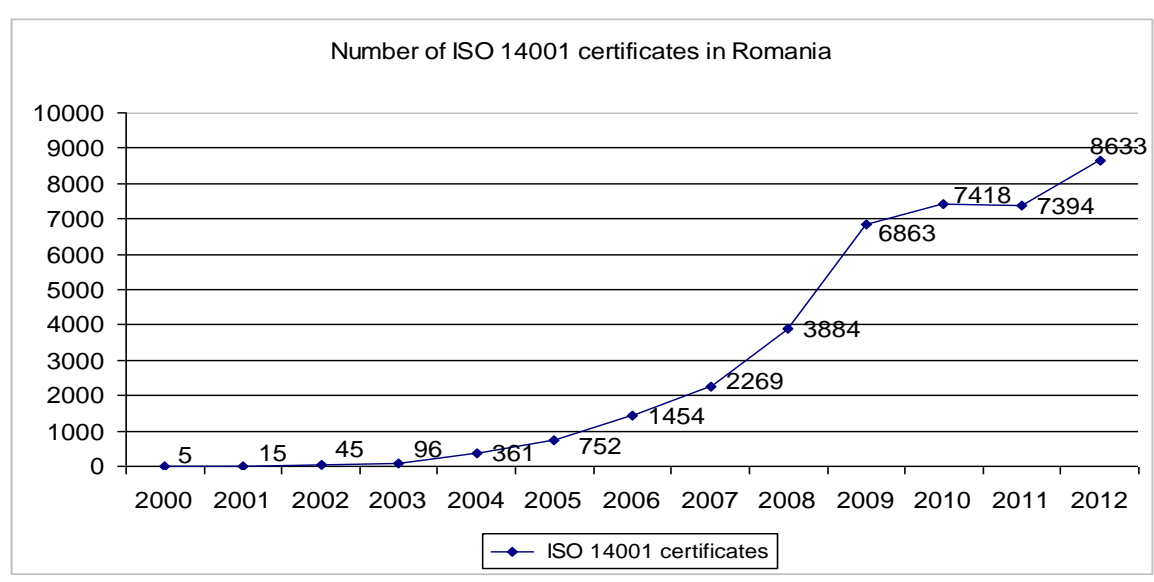

Figure no. 2 - Dynamics of ISO 14001 certificates in Romania

The number of organizations with an environmental management system, according to the Eco-Management and Audit Scheme (EMAS) regulation in the EU-27 has increased significantly over the past years (figure 3 provide the distribution). This trend indicates rising interest from companies, public authorities and other organizations in improving ecological performance while ensures the growth of their prestige and credibility among stakeholders. At the time being EMAS is the most credible and robust environmental management system on the market. According to the latest statistics in 2012 at the EU-27 level were nearly 4.452 EMAS registered organizations on 8.580 sites (figure 3 ).

In the period 2004-2012 the number of organizations registered has increased by 5\% on average per year whereas the number of sites with an environmental management system according to the EMAS regulation has grown by $9 \%$ per year. The highest increase in EMAS registrations by organizations was observed in $2007(11.4 \%)$.

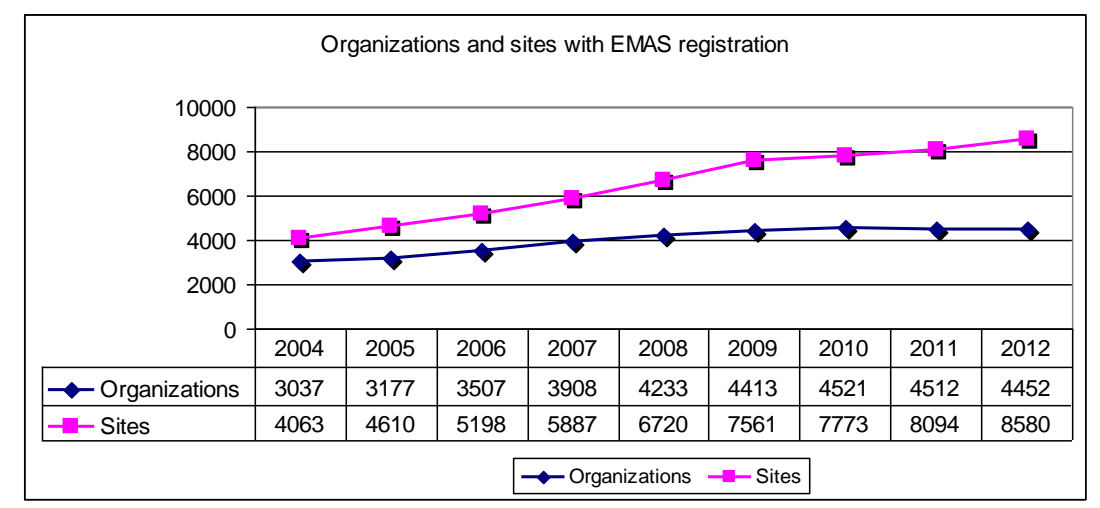

Figure no. 3 - The distribution of EMAS sites and organizations within EU-27

However, the distribution of registered organizations across Member States is markedly uneven. Germany, Spain and Italy stand out in their total number of registrants. In 2012, at the EU27's level, EMAS was implemented in 4.452 organizations and companies, among which $28.32 \%$ were in Spain, $27.22 \%$ in Germany, and $25,85 \%$ in Italy. While amongst the newer Member States only the Czech Republic has a significant number of registered organizations (26 in 2012). (E.C, Eurostat databases, 2013). These large differences between countries may be a result of different national administrative rules and incentives for EMAS registration. For example a study on Italian companies registered under EMAS identify that the main driver for EMAS adoption is the external pressures of Public Authorities (Daddi et al, 2013). This result can be linked with the "nature" of EMAS registration that unlike ISO 14001 is an environmental policy tool based on a public system. 
The number of companies registered under EMAS is far less than ISO 14001 certifications in Romania, due to several reasons: it is more challenging and demanding to achieve an EMAS registration than an ISO 14001 certification and before 2010 EMAS was not recognized worldwide, but only on European markets. As we can notice in figure 4, in 2007 Romania had only one organization registered under the EMAS regulation. During 2007-2011 the number of organizations and sites certified by EMAS has grown to 6, but in 2012 only 4 companies were able to maintain their registration.

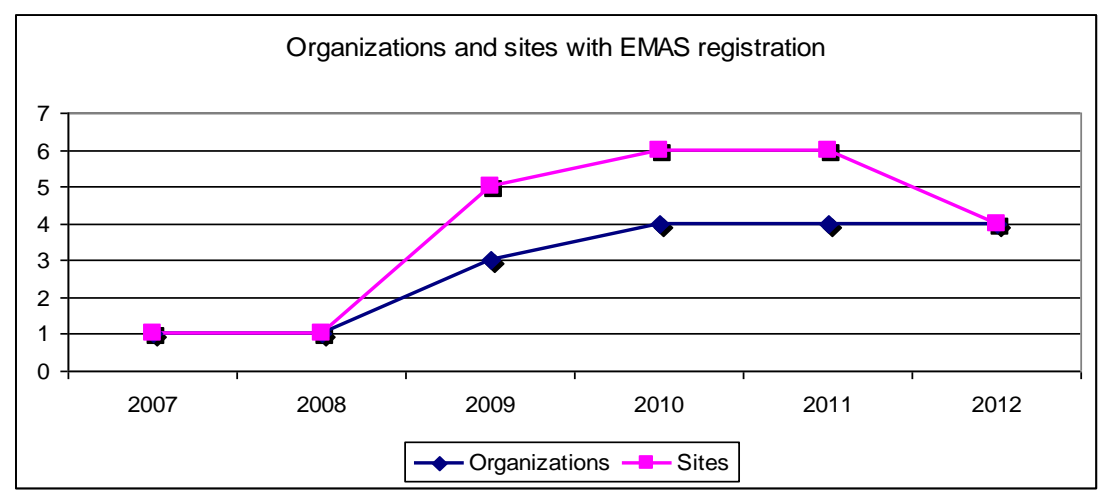

Figure no. 4 - The distribution of EMAS organizations and sites in Romania

A partial explanation for this might be that long-term EMAS registrants face difficulties in meeting the ongoing demand for improvements in environmental performance, as required by the scheme. Indeed EMAS goes one step further than ISO 14001 and has stringent requirements, asking organizations to make public available their environmental policy, objectives, targets and also commitment to performance improvement. Also the costs associated with certification and registration is a key barrier to EMAS registration, especially for SMEs. The updated list of Romanian companies with EMAS certification is presented in table one. We can notice that in 2013 another two organizations were registered to EMAS (Gremlin Computer Company having registered 4 sites) which determines the trend to be again an upward one. We consider that the most important for these companies is succeed to maintain their certification on long term, proving a good environmental performance to all interested parties of their activities.

Table no. 1

The list of EMAS registered companies in Romania - updated 2013

\begin{tabular}{|l|l|l|c|c|c|c|}
\hline & \multicolumn{1}{|c|}{$\begin{array}{c}\text { Name of } \\
\text { organization }\end{array}$} & Field of activity & $\begin{array}{c}\text { Number of } \\
\text { employees }\end{array}$ & $\begin{array}{c}\text { Registration } \\
\text { date }\end{array}$ & $\begin{array}{c}\text { Certificate } \\
\text { validity }\end{array}$ & $\begin{array}{c}\text { Environment } \\
\text { al statement }\end{array}$ \\
\hline 1 & $\begin{array}{l}\text { Zona Metropolitana } \\
\text { Oradea }\end{array}$ & $\begin{array}{l}\text { Non-profit } \\
\text { organization }\end{array}$ & - & $2007 / 2011$ & 2014 & Yes \\
\hline 2 & $\begin{array}{l}\text { Ecorec Company } \\
\text { Tulcea }\end{array}$ & Waste landfill & 90 & 2011 & 2014 & - \\
\hline 3 & $\begin{array}{l}\text { Triada Prod Impex } \\
\text { Company Bucuresti }\end{array}$ & $\begin{array}{l}\text { Construction } \\
\text { works }\end{array}$ & 53 & 2011 & 2014 & Yes \\
\hline 4 & $\begin{array}{l}\text { Druckfarben } \\
\text { Romania }\end{array}$ & $\begin{array}{l}\text { Manufacture of } \\
\text { paints, } \\
\text { varnishes, } \\
\text { printing ink }\end{array}$ & 85 & 2012 & 2015 & Yes \\
\hline 5 & $\begin{array}{l}\text { Gremlin Computer } \\
\text { Company }\end{array}$ & $\begin{array}{l}\text { Treatment and } \\
\text { disposal of non- } \\
\text { hazardous waste }\end{array}$ & 98 & 2013 & 2016 & Yes \\
\hline 6 & $\begin{array}{l}\text { Monstanta Carpati } \\
\text { Company, Prahova }\end{array}$ & $\begin{array}{l}\text { Constructionwo } \\
\text { rks }\end{array}$ & 56 & 2013 & 2016 & Yes \\
\hline
\end{tabular}

Source: http://www.anpm.ro/upload/92957_EMAS_2013.pdf (National Register EMAS) 
Although in Romania, in comparison with the situation from the other developed countries of EU, the number of EMAS certified organizations is still low, we consider that in the next period this number can be higher for the following reasons. In our country we identified a high number of environmental management systems certified to ISO 14001. Taking into account that EMAS II integrate ISO 14001 requirements we consider that is easier for the organizations that have already ISO14001 certification to obtain even EMAS registration that is more agreed at European level. Because ISO 14001 is considered as a stepping-stone to EMAS, it means that the most important step towards have been taken. Furthermore, due to higher requirements an EMAS registration automatically qualifies an organization for an ISO 14001 certification. EMAS enables companies to gain a competitive advantage by achieving cost reductions, by saving resources and demonstrating their serious commitment to reducing environmental impacts of their operations. Also, sum of these measures enhances employee motivation and increases performance quality, making the competitiveness of company even stronger. An EMAS registration will provide organizations with improved communication possibilities through certified third-party auditing and a validated environmental statement.

On the other hand SMEs are facing internal and external barriers when seeking to address their environmental issues and implement EMS. Many SMEs in particular may be engaging in environmental management systems in order to ensure compliance with environmental regulations and/or to reduce costs of resource inputs and waste management, but may not be registering under EMAS or ISO 14001. However, European countries have already realized this problem and different initiatives have been explored trying to improve the EMS implementation and to encourage companies to certify. There are some proven methods, especially for SME's, for achieving a complete EMAS registration without excessive effort, for example the so-called cluster concept and EMASeasy (http://ec.europa.eu/environment/emas).

Regarding EMAS registration it is important to know that SMEs of our country benefit from some incentives: reduction of registration fees with 25\%; no fees for additional assistance and information on environmental legal requirements; extending external audit frequency from 3 to 4 years. Also EMAS verifier shall take into account special characteristics of SMEs such as communication, multifunctional staff, education and documentation. Also legislation specifies that EMAS registration can be a criterion for the allocation of points, regarding public procurement. As we can notice in table one, all Romanian companies registered under EMAS until now are medium sized (if we refer to the number of employees). Some authors (Biondi et al, 2000) consider that the difficulties may SMEs experience in fully understanding and satisfying some EMAS requirements (definition of criteria for selecting significant aspects, measurement of continual improvement, writing and publication of an environmental statement) are mostly due to their lack of technical expertise in this area. We recommend the provision of support to SMEs in writing the environmental statements through subsidies for consultants.

A step-up from ISO 14001 to EMAS can provide organizations with significant additional benefits. EMAS offers the advantage of being legally recognized through a European Council Regulation and certified organizations are listed in a public register. Another reason is the fact that EMAS is integrated into the Sustainable Consumption and Production and Sustainable Industrial Policy Action Plan of the EU (Report EMAS, 2011). Taking into account that Romania is an EU member, EMAS adoption must be seen as a long term strategy that can help organizations to eliminate barriers to entry in certain markets. Blending EMAS into strategic management decisions ensures that the entire organization contributes to the continuous improvement of environmental and economic performance. 


\section{Conclusions}

Environmental management systems (EMS) are a potentially useful tool to assist companies in identifying and reducing the environmental impact of their operations as well as in achieving economic benefits. Among companies operating in international markets, ISO 14001 or EMAS certifications is an indicator of environmental responsibility and is often seen as a way of developing competitive advantage. The benefits of positively addressing environmental issues therefore not only cover the preservation of the environment, but are also linked to business performance and profitability while improving the corporate image, enhancing access to export markets, providing a common reference for communicating environmental issues with customers, regulators, the public and other stakeholders, etc.

Regarding certified EMS from Romanian, results show a large discrepancy between the number of ISO 14001 and EMAS certification. Regarding ISO14001 certification, Romania is situated on $7^{\text {th }}$ in the world $(8,633)$, meanwhile the number of EMAS certified organizations is still low, mainly due to more stringent requirements and the lack of information about the benefits of EMAS that go beyond those achievable under ISO 14001. Indeed organizations that choose for the EMAS registration enter into a process that is strongly influenced by the involvement of the competent authorities in the verification phases. This results in both an opportunity for developing transparent and collaborative relations with relevant public and private stakeholders and a stronger pressure towards tangible and continuous improvements in environmental performance. In order to facilitate EMAS registration, we suggest promoting the cluster approach to registration through the provisions of EU guidance and seminars to share best practice between competent bodies. Also we consider that public authorities play an important role in promoting environmental consciousness and sustainable development and increasing the uptake of EMSs among organizations. Taking into account that EMAS in an European regulation, public authorities at all levels should design and implement comprehensive and pro-active strategies to achieve a significantly higher uptake of the scheme. At the same time it is important that SMEs to be aware of existing incentives for EMAS registration.

In our opinion the combination of the ISO 14001 EMS with additional requirements provided by EMAS not only increase the companies' ability to have a long term affect on environmental performance, but also validates that the ISO 14001 is a good basic environmental tool, that can be used to build a meaningful environmental management program. The two standards do not exclude each other contrary implementing one facilitates certification to other, increasing benefits that companies can get.

We consider that during this time of economic uncertainty the continuous growth in the number of companies that are certified demonstrates that investing in environmental measures plays a fundamental role in helping companies and economies build a sustainable future. More and more large companies request environmental commitment in their supply chain and therefore we suggest for companies (especially SMEs) to have an EMAS or ISO 14001 certifications in order to gain market access and make it easier to find business partners. Future research should analysis more deeply the environmental statement of companies registered under EMAS, in order to identify the indicators used to evaluate and report the environmental performance. Also the correlation between business performance and environmental performance should be taken into consideration.

References:

1. Biondi V., Frey M., Iraldo F., 2000. EMS and SMEs - motivations, opportunities and barriers related to EMAS and ISO 14001 implementation, Greenleaf Publishing

2. Boiral O., Henri J. F., 2012. Modelling the impact of ISO 14001 on environmental performance. A comparative approach, Journal of Environmental Management, Vol. 99, available at http://dx.doi.org/10.1016/j.jenvman.2012.01.007 accessed on 21 March 2014. 
3. Brouwer M. A. C., van Koppen C. S. A., 2008. The soul of the machine: continual improvement in ISO 14001, Journal of Cleaner Production, Vol. 16 (4)

4. Clausen J., Keil M., Jungwirth M., 2002. The State of EMAS in the EU Eco-Management as a Tool for Sustainable Development - Literature Study, Brussels, Belgium June

5. Comoglio C., Botta S., 2012. The use of indicators and the role of environmental management systems for environmental performances improvement: a survey on ISO 14001 certified companies in the automotive sector, Journal of Cleaner Production, Vol. 20 (1), available at http://www.sciencedirect.com/science/article/pii/S0959652611003301, accessed on 18 March 2014

6. Daddi T., Tessitore S., Testa F., Iraldo F., 2013. Environmental performance improvements and external stakeholder pressures in companies with certified Environmental Management System, Proceedings of the 2013 International Conference on Energy, Environment, Ecosystems and Development

7. Daddi T., Magistrell, M., Frey M., Iraldo F., 2011. Do environmental management systems improve environmental performance? Empirical evidence from Italians companies, Environment, Development and Sustainability Journal, Vol. 3 (5)

8. Directorate-General for Environment (DG ENV), Number of ISO 14001 certified companies in European countries, http://database.eco-innovation.eu/indicators/index/search:ISO accessed on 17 March 2014.

9. Edwards A. J., 2004. Introduction to environmental management. In ISO 14001 Environmental Certification Step by Step, Butterworth-Heinemann Publishing, Oxford

10. ENDS, 2013. Road from Rio - The past, the present and the future of ISO 14001, available at http://www.bsigroup.com, accessed on 31 January 2014

11. Eurostat, Organizations and sites with EMAS registration, http://www.eea.europa.eu/data and-maps/figures/number-of-organizations-with-registered, accessed on 17 March 2014

12. Franchetti M., 2011. ISO 14001 and solid waste generation rates in US manufacturing organizations: an analysis of relationship, Journal of Cleaner Production, Vol. 19 (9-10)

13. Freimann J., Walther M., 2002. The Impacts of Corporate Environmental Management Systems - A Comparison between EMAS and ISO 14.001, ASY-ECO Evaluation of Sustainability, EuroConference, Vienna

14. Gara S., Mühlberger M., 2006. Beyond EMAS: Sustainability Management System. Just another buzzword?, EMICO Conference Proceeding, Vienna

15. ISO Survey, 2012, http://www.iso.org/iso/home/standards/certification, accessed on 17 March 2014

16. Matuszak-Flejszman A., 2009. Benefits of EMS in Polish Companies compliant with ISO 14001, Polish Journal of Environmental Studies, Vol. 18, No. 3

17. Morrow D., Rondinelli D., 2002. Adopting Corporate Environmental Management Systems: Motivations and Results of ISO 14001 and EMAS Certification, European Management Journal, Vol. 20, No. 2, available at http://gse.cat.org.uk/downloads/isoemasmotivation_paper.pdf, accessed on 11 March 2014.

18. National Agency for Environmental Protection. National Register EMAS, available at http://www.anpm.ro/upload/92957_EMAS_2013.pdf, accessed on 15 March 2014

19. Nishitani K., 2010. Demand for ISO 14001 adoption in the global supply chain: An empirical analysis focusing on environmentally conscious markets, Resource and Energy Economics 32

20. Neugebauer F., 2012. EMAS and ISO 14001 in the German industry - complements or substitutes? Journal of Cleaner Production, vol. 37, available at https://www.fkit.unizg.hr/_download/repository/seminar_3.pdf, accessed on 21 March 2014 
21. Report EMAS 2011. Creating added value with EMAS, Differences between ISO and EMAS, available at http://www.emas.de/fileadmin/user_upload/06_service/PDFDateien/Creating_Added_Value_with_EMAS.pdf

22. Rondinelli D., Vastag G., 2000. Panacea, Common Sense, or Just a Label? The Value of ISO 14001 Environmental Management Systems, European Management Journal, Vol. 18, No. 5

23. Searcy C., Morali O., Karapetrovic S., 2012. An analysis of ISO 14001 and suggested improvements, Journal of Global Responsibility, Vol. 3, No. 2, Emerald Group Publishing Ltd

24. Testa F., Rizzi F., Daddi T., Gusmerotti N., Frey M., Iraldo F., 2014. EMAS and ISO 14001: differences in effectively improving environmental performance, Journal of Cleaner Production, Vol. 68

25. The European Eco-Management and Audit Scheme, Improving your Environmental and Business Performance, available at http://ec.europa.eu/environment/emas/index_en.htm accessed on 31 January 2014. 